Provided for non-commercial research and education use. Not for reproduction, distribution or commercial use.

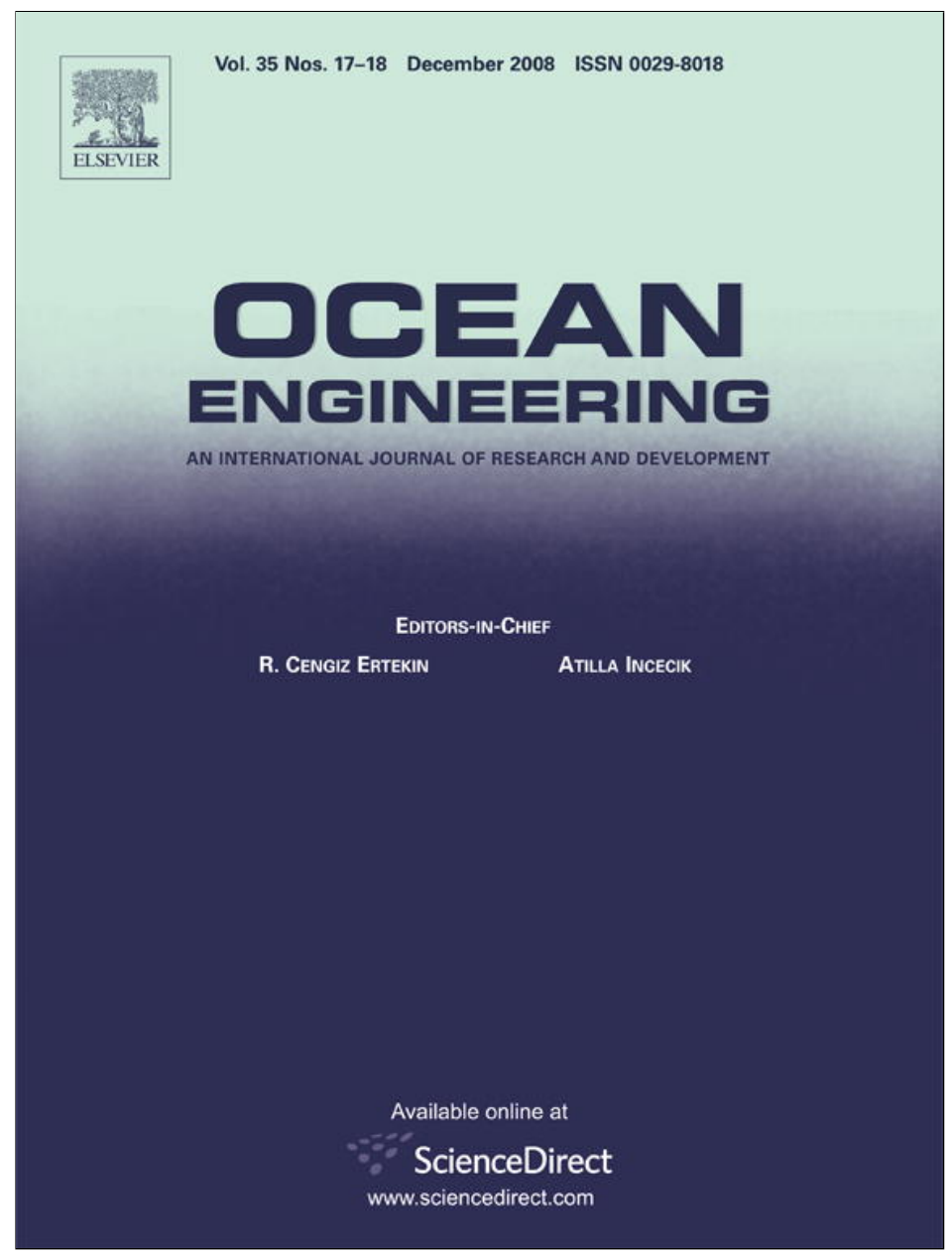

This article appeared in a journal published by Elsevier. The attached copy is furnished to the author for internal non-commercial research and education use, including for instruction at the authors institution and sharing with colleagues.

Other uses, including reproduction and distribution, or selling or licensing copies, or posting to personal, institutional or third party websites are prohibited.

In most cases authors are permitted to post their version of the article (e.g. in Word or Tex form) to their personal website or institutional repository. Authors requiring further information regarding Elsevier's archiving and manuscript policies are encouraged to visit:

http://www.elsevier.com/copyright 


\title{
Efficient multivariable submarine depth-control system design
}

\author{
Eduardo Licéaga-Castro $^{\mathrm{a}, *}$, Jesús Licéaga-Castro ${ }^{\mathrm{b}}$, Carlos E. Ugalde-Loo $^{\mathrm{c}}$, Eva M. Navarro-López ${ }^{\mathrm{d}}$ \\ a Departamento de Ingeniería de Sistemas y Automática, Universidad Carlos III Leganés, 28911 Madrid, Spain \\ ${ }^{\mathrm{b}}$ Departamento de Ingeniería Mecánica y Mecatrónica, ITESM-CEM 52926 Mexico City, Mexico \\ ${ }^{\mathrm{c}}$ Department of Electronics and Electrical Engineering, University of Glasgow, Glasgow, Scotland G12 8LT, UK \\ d School of Computer Science, Centre for Interdisciplinary Computational and Dynamical Analysis, University of Manchester, \\ Oxford Road, Kilburn Building, Manchester, M13 9PL, UK
}

\section{A R T I C L E I N F O}

\section{Article history:}

Received 18 January 2008

Accepted 29 August 2008

Available online 27 September 2008

\section{Keywords:}

Multivariable control systems

Frequency-domain design

Individual channel analysis and design

Submarine

Depth control

\begin{abstract}
A B S T R A C T
An efficient solution for the multivariable submarine control design at low-depth conditions under the influence of wave disturbances is presented. The analysis and control design process is carried out under the framework of individual channel analysis and design (ICAD), which is based on the multivariable structure function (MSF). Classical frequency-domain control techniques based on Bode and Nyquist plots are used. Robustness is stated in terms of gain and phase margins. The closed-loop system includes low-order diagonal controllers facilitating its implementation, assessment, and tuning. ICAD discloses new physical insights of the submarine dynamical behaviour. Previous designs based on diagonal controllers consider the input-output channels defined by pairing the bow hydroplane angle with the depth and the stern hydroplane angle with the pitch angle. The alternative input-output pairing leads to unstable closed-loop systems. This phenomenon is associated with hydroplane reverse control. Here it is shown that MSF-based diagonal controllers can be applied effectively for both sets of channel configurations. Emphasis is placed on satisfying design specifications aiming at maintaining the depth low. The solution presented is more feasible and clearer to apply in practice than those so far reported in the literature.
\end{abstract}

(c) 2008 Elsevier Ltd. All rights reserved.

\section{Introduction}

The analysis and design of low-depth-keeping multivariable autopilots for the well-validated $80-\mathrm{m}$ British submarine model are presented.

Submarines operating at deep submergence can be considered to be in a wave-free environment. This is due to the fact that the effect of wave disturbances decreases exponentially with depth. In general, the design of high submergence submarine depthkeeping controllers is a straightforward task. On the other hand, at shallow submergence, under rough sea conditions and low speed, the design of effective depth-keeping autopilots requires further analysis and full comprehension of the effects of sea-wave disturbances on the boat. Shallow submergence operations rely on keeping the submarine at constant depth relative to a calm surface with zero mean pitch angle (Marshfield, 1991; Marshfield et al., 1992; Williams and Marshfield, 1990, 1991a; Ferranti International, 1993). Low depth-keeping controllers must be designed considering the characteristics of the wave disturbances

\footnotetext{
* Corresponding author. Tel.: +34916245925; fax: +34916249430.

E-mail addresses: eduardo.liceagacastro@uc3m.es (E. Licéaga-Castro), jliceaga@itesm.mx (J. Licéaga-Castro), C.Ugalde@elec.gla.ac.uk (C.E. Ugalde-Loo), eva.navarrolopez@gmail.com (E.M. Navarro-López).
}

whose effects are twofold (Marshfield et al., 1992; Ferranti International, 1993). In the first place, there are regular wave forces and moments associated with short and long wave components. They are referred to as the first-order wave effects. The forces and moments due to short wave components cancel along the hull, whereas the submarine contours the longer period waves. For control design purposes, first-order wave disturbances must be neglected as the hydroplanes cannot produce enough forces and moments to counteract the longer wave effects and the frequency of the shorter wave components are beyond the hydroplanes effective bandwidth. The second effect is associated with the irregular components of the waves which produce an upward net force. It is the average component of this suction force that needs to be counteracted by the depth-keeping controller. At the same time, the controller must ignore the first-order disturbance components in order to avoid saturation and nugatory activity of actuators. High activity of the actuators may reduce the stealth characteristics of the submarine.

Earlier depth-control autopilots were found in German submarines at the end of the II World War (Burges, 1975). It is known that French submarines included improved versions of the German designs after the war (Bovis, 1988). The works of Arentzen and Mandel (1960) and Nonweiler (1961) gave rise to the development of depth-keeping controllers in the UK. These earlier 


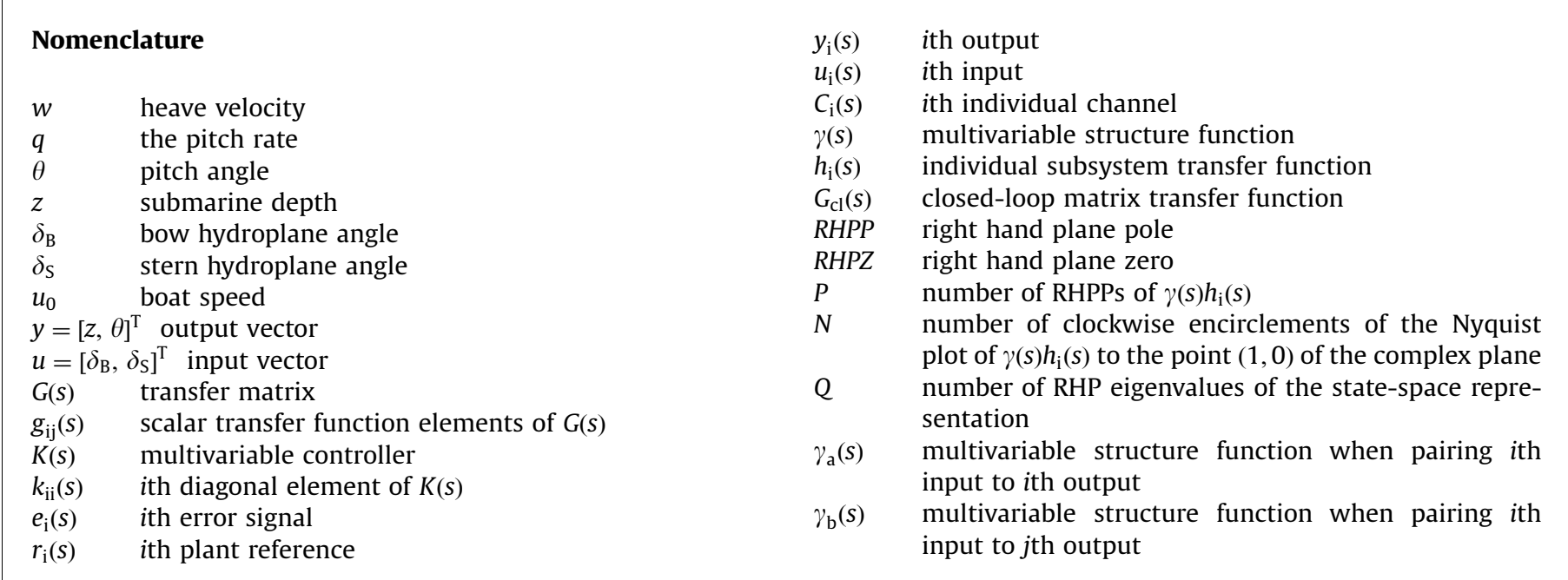

controllers are typical single-input single-output (SISO) PD-type designs in which bow and stern hydroplanes are geared together. Although the details with regard to the performance of these earlier autopilots is not public, it is known that the 'split plane mode', that is, the independent use of bow and stern hydroplanes improves the performance of depth-keeping controllers (Braugnier, 1966). This fact motivated the research on multivariable depthkeeping control systems. In the UK such work was carried out as a joint venture between the University of Cambridge and the Royal Admiralty (Haslar, UK) in which optimal control with Kalman filter methods were applied. Some of the results obtained are reported in Booth (1983), Daniel (1981), Richards and Stoten (1981), Daniel and Richards $(1982,1983)$. Similar works are reported by Gueler (1989), Zhao and Yan (1989) and Lively (1983). By considering the shallow-depth-keeping of submarines as a multivariable control problem, some improvements are achieved. Sea trial results are not of public domain; nevertheless, it is claimed in Lively (1983) that under sea disturbances, the performance is still poor with such control schemes. Kalman filters were also considered in order to cope with sea disturbances. However, in Daniel and Richards (1982), it is reported that the results obtained were less successful than those expected.

Robust control theory opened up new options for developing better designs. This approach was used by the British Defence Research Agency (Marshfield, 1991; Williams and Marshfield, 1990, 1991a, 1991b). These reports show better performance than earlier designs. Nevertheless, a clear and appropriate manner for selecting a good set of weighting functions was and is still lacking. In order to determine a clear and systematic manner for designing depth-keeping controllers, further work was developed by the British Defence Research Agency and the Industrial Control Centre of Strathclyde University. Some of the results obtained during that research programme are reported in Licega-Castro and van der Molen (1995a, b). The main contribution of Liceaga-Castro and van der Molen (1995a) is the definition of a set of control design specifications. These were tailored bearing in mind the wave disturbances effects on the boat and their influence on the activity of the control system. That is, the control specifications were defined in such a way that the controller ignores the regular wave disturbances forces but reacts effectively to the irregular wave effects. The controller presented is obtained considering measurement of the pitch angle, heave velocity, and depth. On the other hand, the work presented in Liceaga-Castro and van der Molen (1995b) defines a systematic and clear design procedure using robust techniques considering the design specifications defined in
Liceaga-Castro and van der Molen (1995a). Nevertheless, the selection of linear wave models for design purposes is not an easy task.

The analysis of the dynamical structure of the submarine model used in Liceaga-Castro and van der Molen (1995a) and Liceaga-Castro and van der Molen (1995b) is presented through the ICAD framework in Liceaga-Castro and Liceaga-Castro (1998). In this work, only the pitch angle and depth measurement are considered available for feedback. The main result presented in Liceaga-Castro and Liceaga-Castro (1998) is that the fundamental aspects for designing effective diagonal low-depth-keeping submarine controllers are established. Such specifications are defined in terms of bandwidth, stability margins and roll-off slope.

A key conclusion derived from the nonlinear simulations results reported in Liceaga-Castro and van der Molen (1995a) and Liceaga-Castro and van der Molen (1995b) is that, regardless of the method used to design the controller, the success of the design depends on satisfying the design specifications defined in Liceaga-Castro and van der Molen (1995a).

The aim of this paper is to formalise the ICAD design procedure of low-depth-keeping submarine controllers and to complement the results presented in Licega-Castro and van der Molen (1995a, b) and Liceaga-Castro and Liceaga-Castro (1998). In addition, concluding aspects with regard to the comparison of the nature of the controllers obtained under the ICAD framework and the so-called robust methods are stated. For instance, the ICAD approach allows to satisfy design specifications (robustness and performance) and avoids unnecessary sophisticated controllers in a clear and transparent constructive manner. Unlike $H^{\infty}$-related methods (Liceaga-Castro and van der Molen, 1995b), in the ICAD-based approach, the characteristics of the submarine dynamical structure are not hidden. Furthermore, new physical characteristics are revealed. Namely, it is shown that by analysing the MSF, it is possible to design multivariable diagonal stabilising controllers for every input-output channel configuration. A diagonal control in which the input-output channels are defined by pairing stern hydroplanes with depth and bow hydroplanes with pitch results in an unstable closed-loop system, which gives rise to the reverse hydroplane control effect (Spencer, 1980).

A crucial aspect of ICAD is that robustness for multivariable systems is expressed in terms of gain and phase margins, which are well-proven robustness measurements in engineering practice. Thus, the lack of robustness pointed out in Keel and Bhattacharyya (1997) and Nesline and Zarchan (1982), associated with modern techniques, is avoided. 
The main contributions of this paper are shown in Sections 3-5. The conditions that a diagonal stabilising controller should satisfy are defined by Proposition 1 in Section 3. A consequence derived from this proposition is that it is not necessary to stabilise the diagonal elements of a multivariable system in order to achieve close-loop stability. In Section 4, the MSF-based system analysis of the submarine depth dynamics is carried out. Two input-output configurations corresponding to two sets of diagonal controllers are defined. One input-output configuration is defined by pairing the bow hydroplanes angle with the depth and the stern hydroplanes angle with the pitch angle. This is the typical configuration. The other input-output configuration is defined by pairing the stern hydroplane angle with the depth measurement and the bow hydroplane angle with the pitch angle. This latter configuration has so far been avoided since it leads to unstable closed-loop systems. Here, this drawback is overcome thanks to Proposition 1. In previous reports on submarine dynamics, it is recognised that if stern hydroplanes are used to control depth and bow hydroplanes to control pitch then an unstable closed-loop system is obtained (Spencer, 1980). An explanation for this fact is given in terms of the direction hydrodynamic forces produced by the hydroplanes. Nevertheless, in this paper, it is shown that such a configuration is unstable due to the dynamical structure of the system and that a stabilising controller can be obtained thanks to Proposition 1. This fact gives rise to new physical insights of submarine depth dynamics, which are explained in Section 4.3.

In Section 5, a multivariable control design associated with each possible channel definition is included. A set of robustness measurements accompanies the control designs. Such results are complementary to those obtained in Licega-Castro and van der Molen (1995a, b). It should be noticed that the obtained controllers for both possible channel configurations are stable, minimum phase, diagonal, robust, and of low order compared to those obtained using robust control theory. Moreover, the specifications for effective depth-keeping control under the effect of wave disturbances are satisfied.

\section{Submarine dynamics}

The well-validated longitudinal model of the $80-\mathrm{m}$ standard British submarine has been the centre of attention of several research programmes (Booth, 1983; Daniel, 1981; Daniel and Richards, 1982, 1983; Marshfield, 1991; Marshfield et al., 1992; Richards and Stoten, 1981; Ferranti International, 1993; Williams and Marshfield, 1990, 1991a,b). In particular, the model used in this paper is summarised in Marshfield (1992).

The results reported in Licega-Castro and van der Molen (1995a, b) were obtained by using the six-degrees-of-freedom

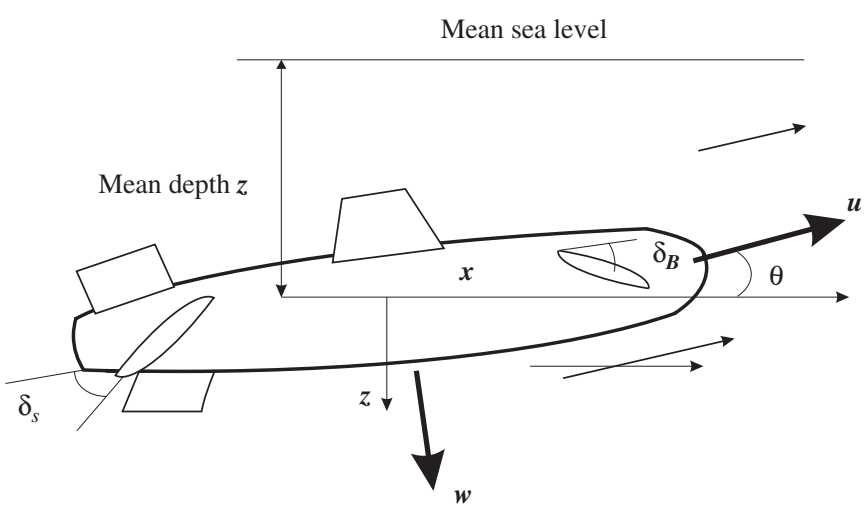

Fig. 1. Submarine depth variables and hydroplanes configuration. nonlinear model from Marshfield (1992) together with the nonlinear wave model reported in Marshfield et al. (1992). Nonlinear simulation results show that it is possible to design effective linear diagonal controllers for the six-degrees-of-freedom submarine. Moreover, the controllers are effective at various speeds by including a simple scheduling gain adjustment. It was found that, for control design purposes the boat depth dynamics can be considered to be dominated by the linearised model.

The variables involved in the depth dynamics of the $80-\mathrm{m}$ standard British submarine are depicted in Fig. 1. Namely: $w$ is the heave velocity, $q$ is the pitch rate, $\theta$ is the pitch angle, $z$ is the submarine depth, $\delta_{\mathrm{B}}$ is the bow hydroplane angle and $\delta_{\mathrm{S}}$ is the stern hydroplane angle.

The frequency-domain depth dynamics with boat speed $u_{0}=$ $3.0867 \mathrm{~m} \mathrm{~s}^{-1}$ can be represented as $Y(s)=G(s) U(s)$ with $y=(z, \theta)^{\mathrm{T}}$, $u=\left(\delta_{\mathrm{B}}, \delta_{\mathrm{S}}\right)^{\mathrm{T}}$ and,

$$
\begin{aligned}
G(s)= & \frac{1}{s(s+0.0629)(s+0.0336+0.0472 \mathrm{i})(s+0.0336-0.0472 \mathrm{i})} \\
& \cdot\left(\begin{array}{cc}
-0.0076(s+0.5461)(s+0.0494) & -0.0229(s+0.0604)(s-0.1815) \\
0.0017 s(s+0.0306) & -0.0022 s(s+0.0556)
\end{array}\right) .
\end{aligned}
$$

\section{A summary of individual channel analysis and design}

Individual channel analysis and design (ICAD) was introduced by O'Reilly and Leithead (1991). It is a framework, rather than a method, devised for designing multivariable control systems. Originally ICAD was referred to as individual channel design (ICD). ICAD is based on the analysis of multivariable control systems with diagonal controllers. For instance, consider a 2-input 2output plant $Y(s)=G(s) u(s)$, which is rewritten as,

$\left(\begin{array}{l}y_{1}(s) \\ y_{2}(s)\end{array}\right)=\left(\begin{array}{ll}g_{11}(s) & g_{12}(s) \\ g_{21}(s) & g_{22}(s)\end{array}\right)\left(\begin{array}{l}u_{1}(s) \\ u_{2}(s)\end{array}\right)$

where $g_{\mathrm{ij}}(s)$ represents scalar transfer functions, $y_{\mathrm{i}}(s)$ the outputs, and $u_{\mathrm{i}}(s)$ the inputs of the system, with $i, j=1,2$. If diagonal controller

$u(s)=K(s) e(s)$

is considered, that is,

$\left(\begin{array}{l}u_{1}(s) \\ u_{2}(s)\end{array}\right)=\left(\begin{array}{cc}k_{11}(s) & 0 \\ 0 & k_{22}(s)\end{array}\right)\left(\begin{array}{l}e_{1}(s) \\ e_{2}(s)\end{array}\right)$,

with $e_{\mathrm{i}}(s)=r_{\mathrm{i}}(s)-y_{\mathrm{i}}(s)$, where $r_{\mathrm{i}}(s)$ represents the plant references. The input-output pairs are referred to as channels. The open-loop input-output channels are clearly defined from Figs. 2 and 3 as,

$C_{\mathrm{i}}(s)=k_{\mathrm{ii}}(s) g_{\mathrm{ii}}(s)\left[1-\gamma(s) h_{\mathrm{j}}(s)\right]$,

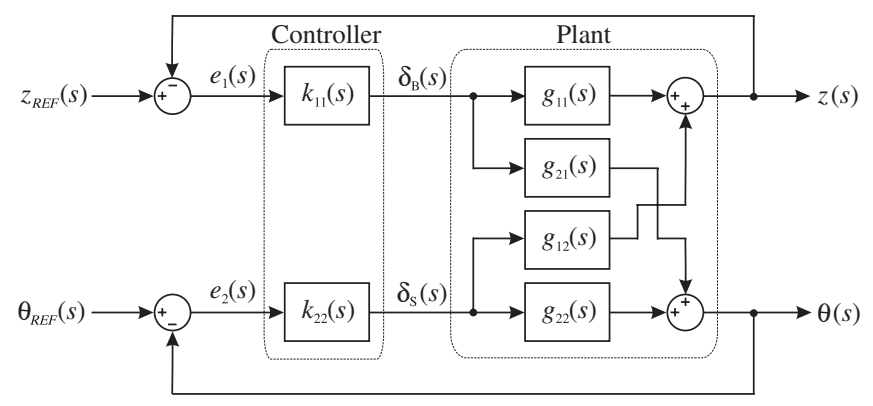

Fig. 2. The 2-input 2-output multivariable control with diagonal controller. 


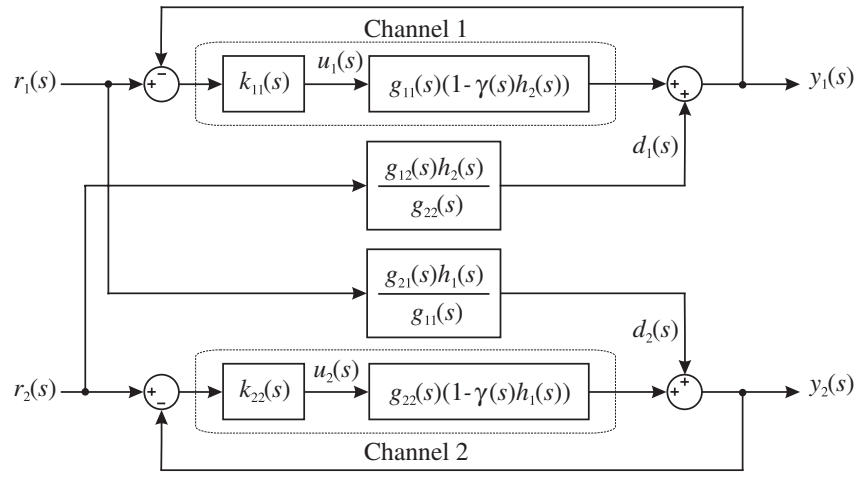

Fig. 3. Equivalent channels of a 2-input 2-output multivariable control system.

where $i, j=1,2$ and $i \neq j$. The complex-valued function

$\gamma(s)=\frac{g_{12}(s) g_{21}(s)}{g_{11}(s) g_{22}(s)}$,

is referred to as the MSF and may be interpreted as a measurement of the coupling between the channels. The functions $h_{\mathrm{i}}(s)$ are

$h_{\mathrm{i}}(s)=\frac{k_{\mathrm{ii}}(s) g_{\mathrm{ii}}(s)}{1+k_{\mathrm{ii}}(s) g_{\mathrm{ii}}(s)}$,

which define the impact of controller $k_{\mathrm{ii}}(s)$ in the $j$ th control loop (with $i \neq j$ ).

From Eqs. (2)-(7), the closed-loop system outputs are

$$
\left(\begin{array}{l}
y_{1}(s) \\
y_{2}(s)
\end{array}\right)=G_{\mathrm{cl}}(s)\left(\begin{array}{l}
r_{1}(s) \\
r_{2}(s)
\end{array}\right),
$$

where $G_{\mathrm{cl}}(s)$ is the closed-loop matrix transfer function and,

$G_{\mathrm{cl}}(s)=(I+G(s) K(s))^{-1} G(s) K(s)$.

The closed-loop system can also be written by relating input $r_{i}$ to output $y_{i}$ with $i=1,2$. For instance:

$y_{\mathrm{i}}(s)=R_{\mathrm{i}}(s) r_{\mathrm{i}}(s)+P_{\mathrm{i}}(s) Q_{\mathrm{i}}(s) r_{\mathrm{j}}(s)$,

where

$R_{\mathrm{i}}(s)=\frac{C_{\mathrm{i}}(s)}{1+C_{\mathrm{i}}(s)}, \quad P_{\mathrm{i}}(s)=\frac{1}{1+C_{\mathrm{i}}(s)}, \quad Q_{\mathrm{i}}(s)=\frac{g_{\mathrm{ij}}(s) h_{\mathrm{j}}(s)}{g_{\mathrm{jj}}(s)}$,

with $i, j=1,2$ and $i \neq j$. Eqs. (8) and (9) are equivalent to Eqs. (10) and (11), that is, no simplifications have been introduced. The system representation given by (8)-(9) contains the same information as the representation (10)-(11) does.

By representing the closed-loop system as in (10)-(11), two very important advantages are gained. First, it is possible to describe the system dynamics in terms of the poles and the zeros explicitly. Second, the relationship between the inputs and the outputs is clearly given by means of the term $R_{i}(s)$. Furthermore, the cross-coupling between channels is suitably expressed by means of the term $P_{\mathrm{i}}(s) Q_{\mathrm{i}}(s)$. Classical control techniques can be applied if the system is described in the form of the individual channels Eq. (10). Moreover, the closed-loop response $y_{i}(s)$ can be considered to be driven by the reference $r_{i}(s)$ subject to the disturbance $r_{j}(s)$. Therefore, controllers $k_{i i}(s)$ can be designed in order to satisfy specifications defined in terms of single-inputsingle-output systems. The nature of the design is determined by the poles and the zeros of the open-loop system. The poles and the zeros of the open-loop channels are summarised in Table 1 (Leithead and O'Reilly, 1992a).
Table 1

Open-loop channel poles and zeros

\begin{tabular}{lll}
\hline Transmittance & Zeros & Poles \\
\hline Channel 1 & Zeros of $1-\gamma(s) h_{2}(s)$ & Poles of $g_{11}(s), g_{12}(s), g_{21}(s), h_{2}(s)$ \\
Channel 2 & Zeros of $1-\gamma(s) h_{1}(s)$ & Poles of $g_{22}(s), g_{12}(s), g_{21}(s), h_{1}(s)$ \\
\hline
\end{tabular}

A fact that should be highlighted is that the open-loop channels (Eq. (5)) are expressed in terms of the multivariable structure function (MSF). The analysis of this function is crucial for determining the capabilities of a system and the existence of controllers for achieving a set of design specifications.

The MSF reveals key dynamical characteristics of the multivariable feedback system. It is clear, from Eq. (5), that a system whose MSF has a magnitude much smaller than one for all frequencies possesses a low degree of cross coupling. That is, the channels may be represented by $C_{\mathrm{i}}(s)=k_{\mathrm{ii}}(s) g_{\mathrm{ii}}(s)$. Besides, from the MSF $\gamma(s)$, the dynamical structure of the multivariable system can be determined. Indeed, the transmission zeros of the openloop matrix transfer function $G(s)$ are the zeros of $(1-\gamma(s))$ which are not poles of $G(s)$ (Leithead and O'Reilly, 1991a). If the system does not have right-hand plane poles (RHPPs), as in the case of the transfer function matrix equation (1), then the transmission zeros of the system are the zeros of $(1-\gamma(s))$. The pole-zero structure of the channels is described in terms of $\gamma(s)$ in Table 1.

In general, the poles of $g_{\mathrm{ij}}(s)$ are known and the poles of $h_{\mathrm{i}}(s)$ are determined as a part of the control design. On the other hand, the zeros of the channels must be checked in order to find out if any of the channels is or can become non-minimum phase. The contribution of $r_{\mathrm{i}}(s)$ to the response of channel $j$ can be studied from the closed-loop response of channel $i$, which is defined by (11). The following result, which was outlined but not proven in Leithead and O'Reilly (1991a), defines an important property of stabilising diagonal controllers.

Proposition 1. Consider the closed-loop system equation (10) where $K(s)=\operatorname{diag}\left[k_{11}(s) k_{22}(s)\right]$ is a diagonal controller. If $k_{\mathrm{ii}}(s)$ stabilises $R_{\mathrm{i}}(s)$ and the references $r_{\mathrm{i}}(s)$ and $r_{\mathrm{j}}(s)$ are bounded, then $k_{\mathrm{ii}}(s)$ also stabilises the channel closed-loop output $y_{\mathrm{i}}(s)$, where $i, j=$ 1,2 and $i \neq j$.

Proof. Appendix A.

Another important aspect is that no particular characteristics are assumed for the transfer functions $g_{\mathrm{ij}}(s), g_{\mathrm{ii}}(s)$, and $h_{\mathrm{i}}(s)$ for $i, j=1,2, \quad i \neq j$. The control design and channel performance capabilities are determined by the right-hand plane zeros (RHPZs) of the channels, which are the zeros of $\left(1-\gamma(s) h_{\mathrm{i}}(s)\right)$ according to Table 1. It is well known that RHPZs have adverse effects on the control system performance and sensitivity (Freudenberg and Looze, 1988; Leithead and O'Reilly, 1991b). A preliminary analysis can be performed by assuming that the bandwidth of one of the channels, for instance channel 2, is higher than that of channel 1 . If this is the case, the gain of the controller $k_{22}(s)$ is high over a frequency range which includes the significant dynamics of channel 1. That is, $h_{2}(s)$ is close to one over the required bandwidth of channel 1 . Under these circumstances and according to Eq. (5), channel 1 can be written as

$C_{1}(s)=k_{11}(s) g_{11}(s)[1-\gamma(s)]$.

The potential restrictions on the performance due to nonminimum phase behaviour can be established from the RHPZs or purely imaginary zeros of $(1-\gamma(s))$. Note that the RHPZs of $(1-\gamma(s))$ are the RHP transmission zeros of the multivariable system. Moreover, the system has purely imaginary transmission 
zeros at frequency $s=s_{0}$ if $\gamma\left(s_{0}\right)=1$. Clearly, the complex-valued function $\gamma(s)$ determines the necessary restrictions on $C_{1}(s)$ and, hence, of the controller $k_{11}(s)$. However, in a more general case, $\left(1-\gamma(s) h_{\mathrm{i}}(s)\right)$ is required to have no RHPZs and not $(1-\gamma(s))$. The existence of stabilising controllers for a particular system is determined by $\gamma(s)$, and the design specifications are reflected in $h_{\mathrm{i}}(s)$. As it was pointed out at the beginning of this section, ICAD should be considered a design framework rather than a method. Different plants may present peculiar characteristics reflected on their MSF, and thus it would be rather difficult to establish general design methods. Nonetheless, under the ICAD framework, it is possible to establish all the conditions for the existence and design of controllers. ICAD is not restricted to 2-input-2-output systems. The general case is reported in Leithead and O'Reilly (1992b) and some applications for systems with more than two inputs and two outputs are reported in Akbar et al. (1994), Edwards et al. (2000), Liceaga-Castro (1994) and Ugalde-Loo et al. (2008). Other applications are presented in Ugalde-Loo et al. (2006), Dudgeon and Gribble (1998), Dudgeon et al. (2000) and Fadlalmula et al. (1998).

\section{Dynamical structure of the submarine}

In this section, the 80-m standard British submarine is analysed in the context of the ICAD framework. The analysis of the MSF reveals different and interesting interpretations of facts which are well-known to the submarine control community.

The following analysis is based on investigating the dynamical structure of the input-output channels, that is, the number of RHPPs and RHPZs of each channel. It is clear from Table 1 that the channels RHPPs are the RHPPs of individual transfer functions. On the other hand, the channels RHPZs are the RHPZs of $\left(1-\gamma(s) h_{\mathrm{i}}(s)\right)$. Furthermore, the number of RHPZs $(Z)$ of $(1-$ $\gamma(s) h_{\mathrm{i}}(s)$ ) can be determined by applying the Nyquist stability criterion, which is given in Leithead and O'Reilly (1994) as

$Z=N+P-Q$,

where $P$ is the number of RHPPs of $\gamma(s) h_{\mathrm{i}}(s), N$ is the number of clockwise encirclements of the Nyquist plot of $\gamma(s) h_{\mathrm{i}}(s)$ to the point $(1,0)$ of the complex plane, and $Q$ is the number of RHP eigenvalues of the state-space representation.

The individual input-output channels can be formed by pairing the inputs and outputs as follows:

(a) Bow hydroplane angle $\left(r_{1}\right)$-depth $\left(y_{1}\right)$,

Stern hydroplane angle $\left(r_{2}\right)$-pitch angle $\left(y_{2}\right)$.

With this input-output pairing the open-loop system is:

$$
\left(\begin{array}{l}
y_{1}(s) \\
y_{2}(s)
\end{array}\right)=\left(\begin{array}{ll}
g_{11}(s) & g_{12}(s) \\
g_{21}(s) & g_{22}(s)
\end{array}\right)\left(\begin{array}{cc}
k_{11}(s) & 0 \\
0 & k_{22}(s)
\end{array}\right)\left(\begin{array}{l}
e_{1}(s) \\
e_{2}(s)
\end{array}\right)
$$

The corresponding MSF is

$\gamma_{\mathrm{a}}(s)=\frac{g_{12}(s) g_{21}(s)}{g_{11}(s) g_{22}(s)}$.

This configuration is the typical one when diagonal controllers are considered.

(b) Stern hydroplane angle $\left(r_{2}\right)$-depth $\left(y_{1}\right)$

Bow hydroplane angle $\left(r_{1}\right)$-pitch angle $\left(y_{2}\right)$.

This input-output pairing corresponds to the following openopen loop configuration:

$$
\left(\begin{array}{l}
y_{1}(s) \\
y_{2}(s)
\end{array}\right)=\left(\begin{array}{ll}
g_{11}(s) & g_{12}(s) \\
g_{21}(s) & g_{22}(s)
\end{array}\right)\left(\begin{array}{cc}
0 & k_{12}(s) \\
k_{21}(s) & 0
\end{array}\right)\left(\begin{array}{l}
e_{1}(s) \\
e_{2}(s)
\end{array}\right) .
$$

In this case, the corresponding MSF is

$\gamma_{\mathrm{b}}(s)=\frac{g_{11}(s) g_{22}(s)}{g_{12}(s) g_{21}(s)}$.

In the past, this configuration resulted in unstable closedloop systems. The unstability of the system is associated with reverse hydroplane control (Spencer, 1980). In this section, this problem is overcome by means of the MSF-based design.

\subsection{System analysis with $\gamma_{\mathrm{a}}(\mathrm{s})$}

According to $(1), \gamma_{\mathrm{a}}(s)$ is obtained:

$\gamma_{\mathrm{a}}(s)=-2.3617 \frac{(s+0.0306)(s+0.0604)(s-0.1815)}{(s+0.5461)(s+0.0494)(s+0.0556)}$

and the channels are defined by

$C_{1}(s)=k_{11}(s) g_{11}(s)\left[1-\gamma_{\mathrm{a}}(s) h_{2}(s)\right]$,

$C_{2}(s)=k_{22}(s) g_{22}(s)\left[1-\gamma_{\mathrm{a}}(s) h_{1}(s)\right]$.

The existence and design of stabilising controllers $k_{11}(s)$ and $k_{22}(s)$ can be determined from the characteristics of $\gamma_{\mathrm{a}}(s)$. These
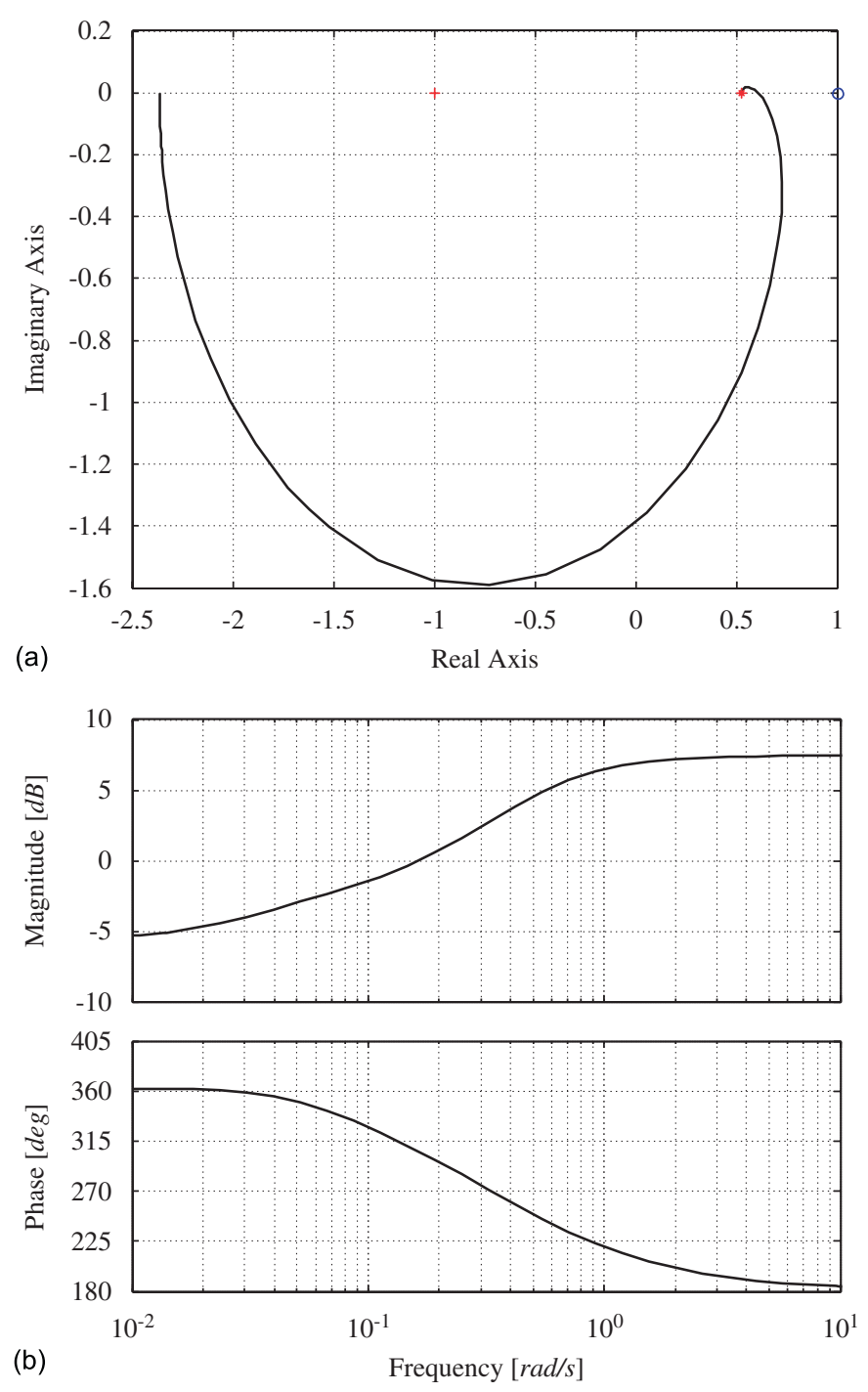

Fig. 4. (a) Nyquist diagram of the MSF $\gamma_{a}(s)$, (b) Bode diagram of the MSF $\gamma_{a}(s)$. 
characteristics can be established by means of the Nyquist plot of $\gamma_{\mathrm{a}}(\mathrm{s})$ (Fig. 4(a)):

(a.1) The magnitude of $\gamma_{\mathrm{a}}(s)$ is less than one as $s$ tends to infinity, that is:

$$
\left(1-\lim _{s \rightarrow \infty} \gamma_{\mathrm{a}}(s)\right)>0
$$

and the Nyquist plot of $\gamma_{a}(s)$ is to the left of the point $(1,0)$ for all frequency values.

(a.2) $\gamma_{a}(s)$ does not contain any RHPP and its Nyquist plot does not encircle the point $(1,0)$. Therefore, $\left(1-\gamma_{\mathrm{a}}(s)\right)$ does not contain any RHPZ.

(a.3) Due to (a.1) and (a.2), functions $h_{\mathrm{i}}(s)$ do not influence the channel structure at high frequency values. That is, the number of encirclements to the point $(1,0)$ by $\gamma_{\mathrm{a}}(s) h_{\mathrm{i}}(s)$ and $\gamma_{\mathrm{a}}(s)$ coincide.

(a.4) For the analysed control configuration, the transfer functions $g_{\mathrm{ii}}(s)$ are minimum phase, thus, in the product

$\gamma_{\mathrm{a}}(s) h_{\mathrm{i}}(s)=\frac{g_{\mathrm{ij}}(s) g_{\mathrm{ji}}(s)}{g_{\mathrm{ii}}(s) g_{\mathrm{jj}}(s)} \cdot \frac{k_{\mathrm{ii}}(s) g_{\mathrm{ii}}(s)}{1+k_{\mathrm{ii}}(s) g_{\mathrm{ii}}(s)}$,

there is not any cancellation of RHPPs of $\gamma_{a}(s)$ with any RHPZs of $h_{\mathrm{i}}(s)$. That is, $k_{\mathrm{ii}}(s)$ must be designed as a stabilising controller of $g_{\mathrm{ii}}(s)$. In this case, the design of stabilising controllers for $g_{\mathrm{ii}}(s)$ is straightforward, since $g_{\mathrm{ii}}(s)$ are stable and minimum phase.

The existence of stabilising controllers for channels (19)-(20) is reduced to the existence of controllers $k_{\mathrm{ii}}(s)$ which stabilise simultaneously

$g_{\mathrm{ii}}(s)\left(1-\gamma_{\mathrm{a}}(s) h_{\mathrm{j}}(s)\right)$ and $g_{\mathrm{ii}}(s)$,

with $i, j=1,2$ and $i \neq j$. The existence of the stabilising controllers $k_{\mathrm{ii}}(s)$ for this case can be established from Result 1 in Leithead and O'Reilly (1991b).

It should be pointed out that the definition of stability margins of the channels is possible if their dynamical structure is preserved. That is, their number of RHPPs and RHPZs do not change. Such a condition can be guaranteed if $h_{\mathrm{i}}(s)$ are designed with appropriate stability margins and the Nyquist plot of $\gamma_{\mathrm{a}}(s) h_{\mathrm{i}}(s)$ does not pass near the point $(1,0)$. Furthermore, such a measure of structural stability can be obtained from the Nyquist (Fig. 4(a)) and Bode (Fig. 4(b)) plots by defining stability margins with respect to the point $(1,0)$. For instance, $\gamma_{a}(s)$ has structural gain margins of 4 and $5 \mathrm{~dB}$ and a structural phase margin of $55^{\circ}$ (Fig. 4). If the level of uncertainty at low frequencies is low (which is usual in practice) these margins are acceptable. It can be concluded that it is possible to design stabilising controllers with no restriction on the channels bandwidths. These controllers may also be designed in order to obtain arbitrarily high bandwidth and arbitrarily small sensitivity (Leithead and O'Reilly, 1991b).

\subsection{System analysis with $\gamma_{\mathrm{b}}(s)$}

The MSF $\gamma_{b}(s)$ for the submarine has the form

$\gamma_{\mathrm{b}}(s)=-0.4234 \frac{(s+0.5461)(s+0.0494)(s+0.0556)}{(s+0.0306)(s+0.0604)(s-0.1815)}$,

and the channels are in this case:

$$
\begin{aligned}
& C_{1}(s)=k_{12}(s) g_{21}(s)\left[1-\gamma_{\mathrm{b}}(s) h_{2}(s)\right], \\
& C_{2}(s)=k_{21}(s) g_{12}(s)\left[1-\gamma_{\mathrm{b}}(s) h_{1}(s)\right] .
\end{aligned}
$$
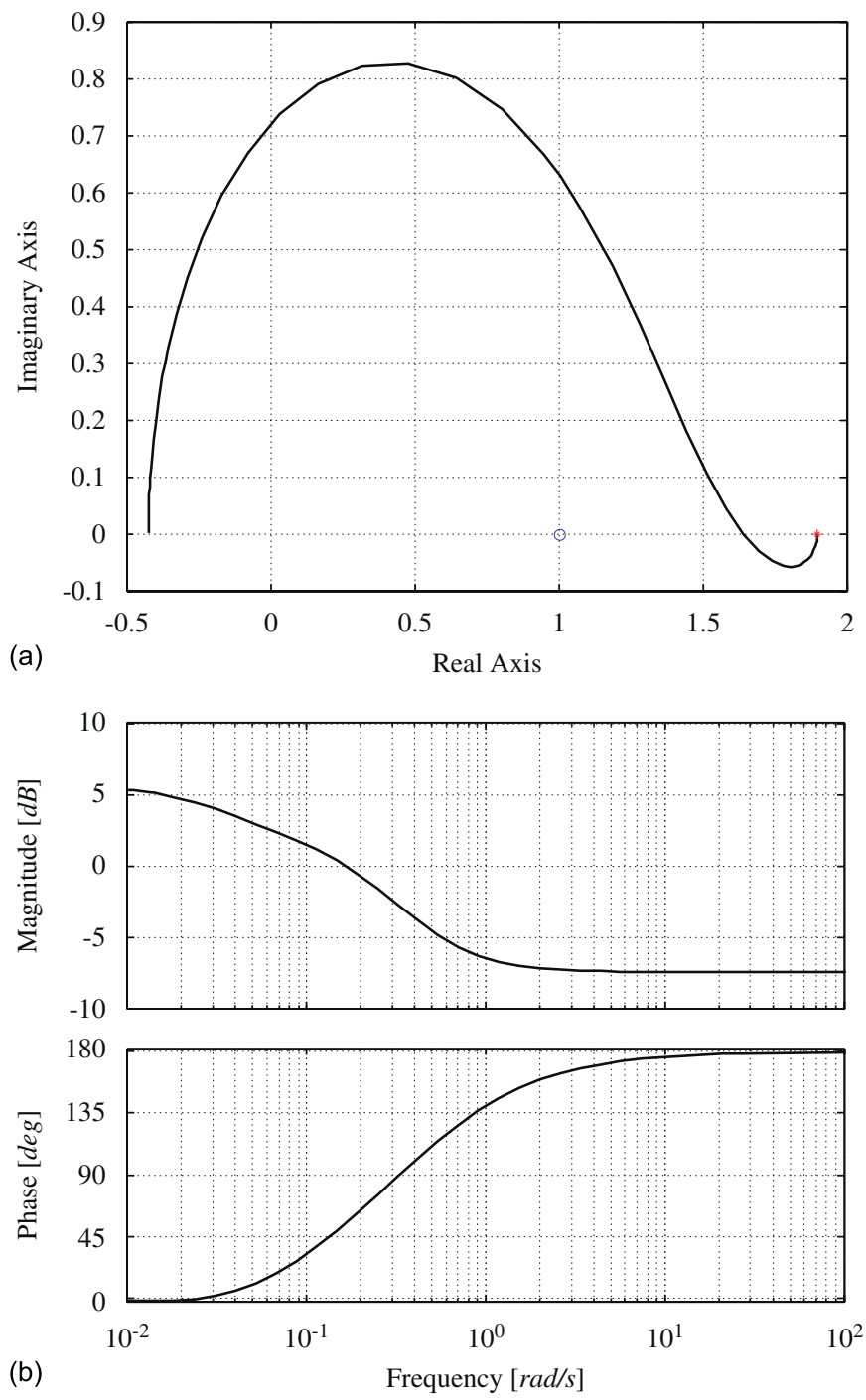

Fig. 5. (a) Nyquist diagram of the MSF $\gamma_{b}(s)$, (b) Bode diagram of the MSF $\gamma_{b}(s)$.

where

$h_{1}(s)=\frac{k_{12}(s) g_{21}(s)}{1+k_{12}(s) g_{21}(s)}, \quad h_{2}(s)=\frac{k_{21}(s) g_{12}(s)}{1+k_{21}(s) g_{12}(s)}$.

As in the previous case, the channels dynamical structure can be analysed in terms of the MSF $\gamma_{\mathrm{b}}(s)$ and its Nyquist plot, shown in Fig. 5(a):

(b.1) The magnitude of $\gamma_{b}(s)$ is less than 1 as $s$ tends to infinity, that is:

$\left(1-\lim _{s \rightarrow \infty} \gamma_{\mathrm{b}}(s)\right)>0$

but in this case, $\gamma_{b}(0)>1$. That is, the Nyquist plot starts to the right of $(1,0)$.

(b.2) $\gamma_{b}(s)$ contains one RHPP and its Nyquist plot encircles the point $(1,0)$ in counterclockwise direction. Thus, $\left(1-\gamma_{\mathrm{b}}(s)\right)$ does not contain any RHPZ.

(b.3) In this case, the functions $h_{\mathrm{i}}(s)$ may influence the channel structure. For instance, the bandwidth of one of the channels may be required to be limited. Obviously, this characteristic will be also reflected in $h_{\mathrm{i}}(s)$. Note that at low frequencies $\left|\gamma_{\mathrm{b}}(s)\right|>1$. Thus, an early roll-off induced by $k_{21}(s)$ may cause $\gamma_{\mathrm{b}}(s) h_{\mathrm{i}}(s)$ not to encircle the point $(1,0)$. In general, it is desirable not only that $\gamma_{\mathrm{b}}(s)$ and $\gamma_{\mathrm{b}}(s) h_{\mathrm{i}}(s)$ preserve the same 
number of encirclements to the point $(1,0)$, but also that their Nyquist plots do not pass near this critical point. Otherwise, the system structure will be highly sensitive with respect to uncertainties. In this case, the system structure can be preserved if the channel roll-off is induced at frequencies at which the Nyquist plot of $\gamma_{\mathrm{b}}(s) h_{\mathrm{i}}(s)$ is to the left of $(1,0)$.

(b.4) It is not difficult to check that in the product

$$
\gamma_{\mathrm{b}}(s) h_{2}(s)=\frac{g_{11}(s) g_{22}(s)}{g_{12}(s) g_{21}(s)} \cdot \frac{k_{21}(s) g_{12}(s)}{1+k_{21}(s) g_{12}(s)},
$$

one RHPP of $\gamma_{\mathrm{b}}(s)$ is cancelled by one RHPZ of $h_{2}(s)$. Thus, in order to keep channel (24) minimum phase, the transfer function $h_{2}(s)$ must contain a RHPP. Moreover, such a RHPP must be placed at a frequency before the roll-off, so that the encirclement of $(1,0)$ is also preserved. Consequently, $k_{21}(s)$ must be designed so that $h_{2}(s)$ contains a RHPP in order to keep the channel minimum phase. In general, if in the product $\gamma_{\mathrm{b}}(s) h_{2}(s), n$ RHPPs are cancelled, then $h_{2}(s)$ must contain $n$ RHPPs in order to keep the channel minimum phase.

Remark 2. The fact that $h_{2}(s)$ is unstable is not relevant, since the stabilisation of the channels does not depend on the stabilisation of the diagonal elements. This fact is shown in Proposition 1. However, if $h_{\mathrm{i}}(s)$ are not stable, the integrity of the system cannot be guaranteed. The product $\gamma_{\mathrm{b}}(s) h_{1}(s)$ in channel (24) does not contain any cancellation of RHPPs with RHPZs. The stabilising controllers of this channel must stabilise $g_{12}(s)\left(1-\gamma_{\mathrm{b}}(s) h_{1}(s)\right)$ and $g_{12}(s)$ simultaneously.

The above facts show that the design of a stabilising controller for channels (23) and (24) is reduced to the design of a controller $k_{12}(s)$ which stabilises simultaneously

$g_{21}(s)\left(1-\gamma_{\mathrm{b}}(s) h_{2}(s)\right)$ and $g_{21}(s)$,

plus the design of a controller $k_{21}(s)$ which stabilises

$g_{12}(s)\left(1-\gamma_{\mathrm{b}}(s) h_{1}(s)\right)$

and forces the closed-loop system

$h_{2}(s)=\frac{k_{21}(s) g_{12}(s)}{1+k_{21}(s) g_{12}(s)}$

to have one RHPP around the same frequency of the RHPZ of $g_{12}(s)$. In addition, the Nyquist plots of $\gamma_{\mathrm{b}}(s) h_{\mathrm{i}}(s)$ must not pass near the point $(1,0)$ so that structural stability is achieved.

The existence of controller $k_{12}(s)$ is determined by Result 1 in Leithead and O'Reilly (1991b). The existence of controller $k_{21}(s)$ is determined by considering a set of plants $G_{g}(s)$, formed by the union of a subset $G_{\mathrm{mp}}(s)$, of minimum-phase plants $g_{\mathrm{mp}}(s)$, and a subset $G_{n m p}(s)$, of non-minimum phase plants $g_{\text {nmp }}(s)$. Clearly, Result 1 in Leithead and O'Reilly (1991b) applies to the plants $g_{\mathrm{mp}}(s) \in G_{\mathrm{mp}}(s)$, so that controllers $K_{\mathrm{mp}}(s)$ which stabilise the plants in $G_{\mathrm{mp}}(s)$ exist. Suppose that the gain of $K_{\mathrm{mp}}(s) g_{\mathrm{mp}}(s)$, where $g_{\mathrm{mp}}(s) \in G_{\mathrm{mp}}(s)$, is greater than 1 for all frequency values larger than the frequency of all the RHPZs of $g_{\text {nmp }}(s) \in G_{n m p}(s)$. Finally, it is necessary to assure that the number of RHPPs of the closed-loop system

$h_{\mathrm{nmp}}(s)=\frac{K_{\mathrm{mp}}(s) g_{\mathrm{nmp}}(s)}{1+K_{\mathrm{mp}}(s) g_{\mathrm{nmp}}(s)}$

coincides with the number of RHPZs of $g_{\text {nmp }}(s)$. This is given by Result 4 in Leithead and O'Reilly (1991b).

Then, stabilising controllers exist for system (26), and these controllers force the closed-loop system (27) to have one RHPP.
Note that, from Fig. 5(b), the gain margins and phase margin of $\gamma_{\mathrm{b}}(s)$ are 4 and $6 \mathrm{~dB}$; and $50^{\circ}$, respectively.

\subsection{Hydroplanes reverse control: new physical insights}

Earlier designs of submarine low-depth-keeping autopilots did not consider the multivariable nature of the boat. Such autopilots were obtained by designing stabilising controllers for the diagonal elements of $Y(s)=G(s) U(s)$. It is well-known to the submarine community that-if only the diagonal elements of the transfer matrix are considered-successful controllers are associated with the pairing defined by $\gamma_{a}(s)$, and that the input-output channels defined by $\gamma_{\mathrm{b}}(s)$ lead to unstable designs (Spencer, 1980).

The unstable characteristic of the designs with the inputoutput pairing of $\gamma_{b}(s)$ was associated with the direction of the hydroplane lift forces in certain manoeuvres. For instance, from Fig. 1, a nose down pitch attitude is required in order to increase the depth. With the channels defined by $\gamma_{b}(s)$, this action requires a positive angle of attack of the bow hydroplanes. In such a manoeuvre, the lift force of the bow hydroplanes is directed upwards. On the other hand, the stern hydroplanes moment is used to level the boat, which also requires upward forces. It was thought that the lift forces prevented the submarine from increasing its depth and eventually led to instability. The phenomenon is referred to as reverse hydroplane control. The analysis of Section 4.2 has shown that the stability problem arising in earlier designs, associated with the channel definitions of $\gamma_{b}(s)$, is due to the dynamical structure characteristics of the boat rather than the direction of the lift forces. Such a stability problem can be solved if $k_{21}(s)$ is designed to induce a RHPP in (27) - at the frequency of the RHPZ of $g_{12}(s)$-rather than stabilising $g_{12}(s)$. This is a revealing conclusion and gives new light on the concept of reverse hydroplane control.

It should be remarked that the reverse control effect has a strong influence if the control surfaces produce high lift forces, as it is the case of missiles guidance problems (Yanushevsky, 2008).

\section{Control design}

\subsection{Design specifications}

The aim of the control system is to maintain the submarine at constant depth relative to a calm surface with zero mean pitch angle (Liceaga-Castro and van der Molen, 1995a, 1995b). The regular wave forces and moments caused by short waves cancel along the hull, whereas the submarine contours the longer waves. The controller must neglect these effects since the hydroplanes cannot produce forces which are large enough to counteract them. The controller should compensate the irregular component of the waves which produces the upward net force. It is the average of this suction force which causes the depth-keeping problem. The suction force resembles a series of occasional bursts of impulses rather than a constant suction force.

In order to avoid saturation and nugatory motion of the hydroplanes due to the wave effects, the bandwidth of the channel corresponding to $\theta$ should be less than $0.5 \mathrm{rad} / \mathrm{sec}$, and the bandwidth of $z$ should be about a decade less than that of the pitch (Liceaga-Castro and van der Molen, 1995a, 1995b). Moreover, the gain corresponding to the depth channel has to be less than $-20 \mathrm{~dB}$ and its slope not less than $-20 \mathrm{~dB} / \mathrm{dec}$ for frequencies higher than $0.4 \mathrm{rad} / \mathrm{s}$. These characteristics were also crucial for the polynomial $H^{\infty}$ design reported in Liceaga-Castro and van der Molen (1995b). The following results, which satisfy the above design specifications, have been obtained by the use of a specially tailored ICAD Matlab Toolbox (Ugalde-Loo et al., 2005). 
Table 2

Structural robustness of the channels and control system using $\gamma_{\mathrm{a}}(s)$

\begin{tabular}{lccccc}
\hline Measure & $C_{1}(s)$ & $k_{11}(s) g_{11}(s)$ & $\gamma_{\mathrm{a}}(s) h_{2}(s)$ & $k_{2}(s)$ & $\gamma_{\mathrm{a}}(s) h_{1}(s)$ \\
\hline Bandwidth (rad/s) & 0.03 & 0.09 & - & 0.5 & 0.508 \\
Gain margin (dB) & 24 & 30 & 6 & - & $\infty$ \\
Phase margin (deg) & 104 & 50 & 50.210 & 6 & $\infty$ \\
\hline
\end{tabular}

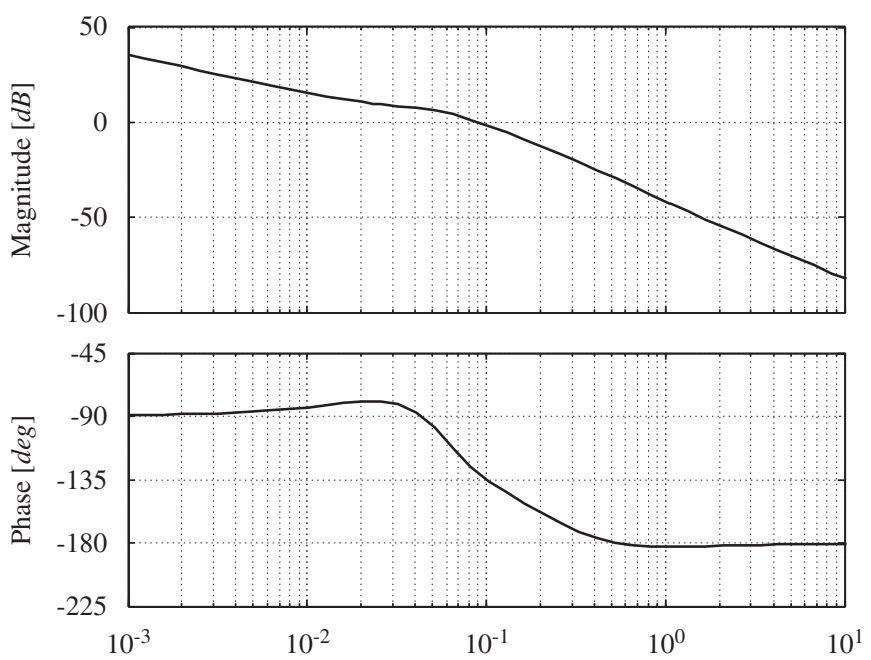

(a)

Frequency $[\mathrm{rad} / \mathrm{s}]$
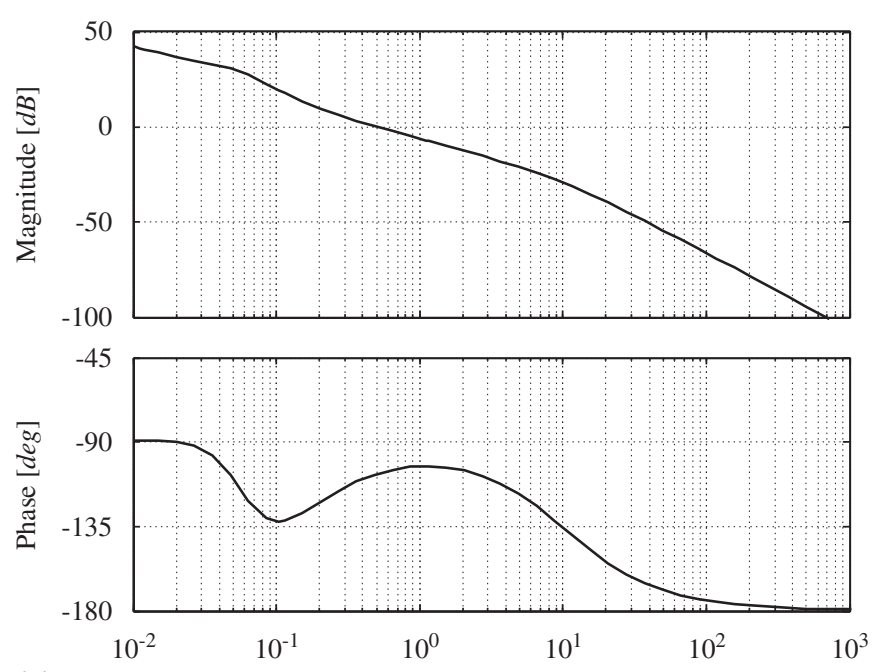

(b)

Frequency $[\mathrm{rad} / \mathrm{s}]$

Fig. 6. (a) Bode diagram of $k_{11}(s) g_{11}(s)$, (b) Bode diagram of $k_{22}(s) g_{22}(s)$.

\subsection{System design with $\gamma_{\mathrm{a}}(s)$}

By using the ICAD Matlab Toolbox reported in Ugalde-Loo et al. (2005), the controllers

$$
\begin{aligned}
& k_{11}(s)=-1.0286 \frac{(s+0.07)(s+0.05)}{(s+0.3)(s+0.2)} \text { and } \\
& k_{22}(s)=-2200 \frac{(s+0.1)^{2}}{s(s+10)}
\end{aligned}
$$

were obtained. The resulting structural robustness of the channels and the control system are shown in Table 2. Information associated with Table 2 is shown in Figs. 6-8.
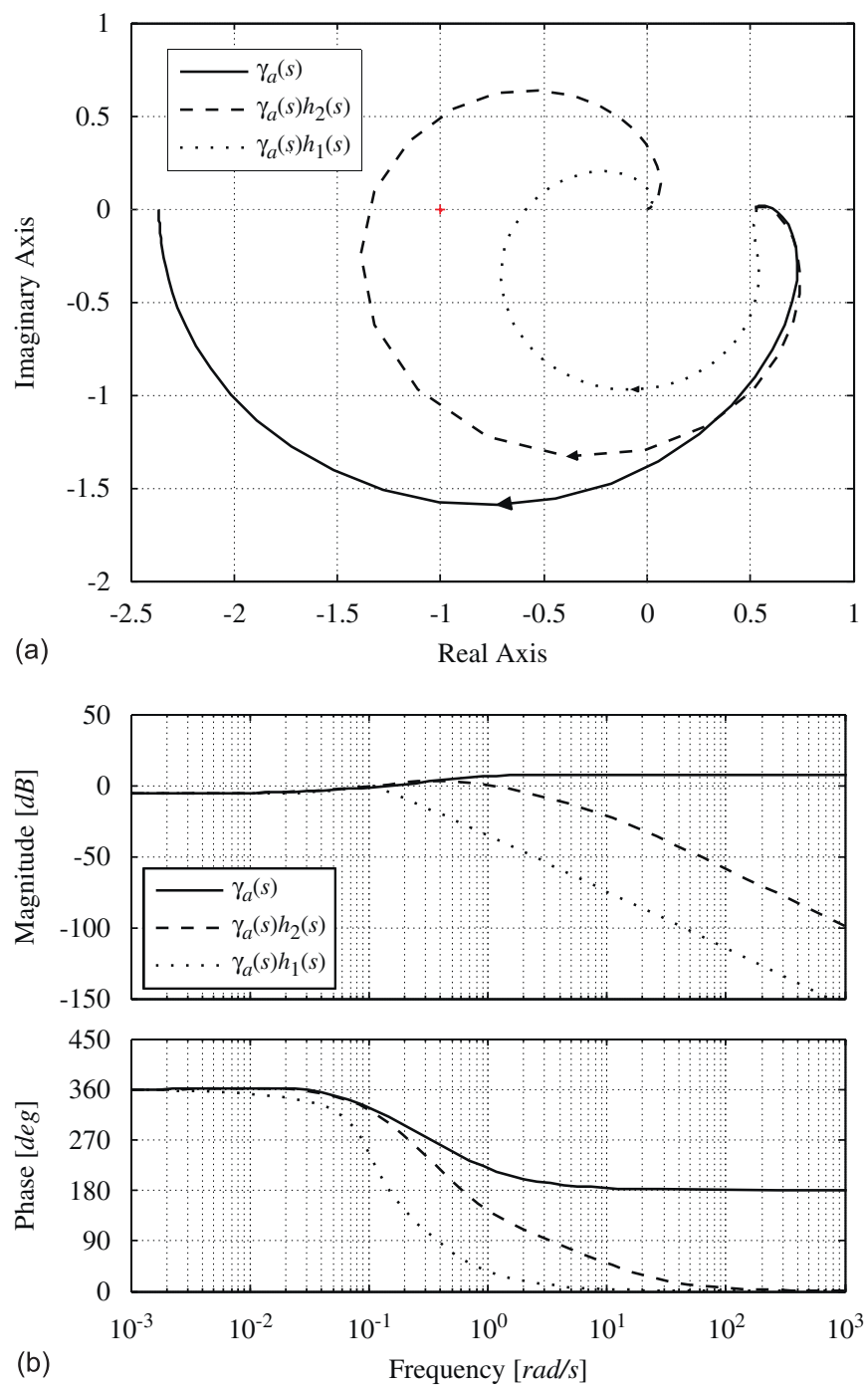

Fig. 7. (a) Nyquist diagrams of $\gamma_{\mathrm{a}}(s) h_{2}(s)$ and $\gamma_{\mathrm{a}}(s) h_{1}(s)$, (b) Bode diagrams of $\gamma_{\mathrm{a}}(s) h_{2}(s)$ and $\gamma_{\mathrm{a}}(s) h_{1}(s)$

In order to avoid sharp responses of the controller to step changes in depth, the reference is filtered according to: $z_{1}(s) / r_{1}(s)$ $=0.000625 /\left(s^{2}+0.05 s+0.000625\right)$.

\subsection{System design with $\gamma_{\mathrm{b}}(s)$}

For the case of $\gamma_{b}(s)$, the controllers

$$
k_{12}(s)=1400 \frac{(s+0.1)(s+0.03)}{s(s+5)} \quad \text { and } \quad k_{21}(s)=-0.4 \frac{(s+0.025)}{(s+0.25)}
$$

were obtained. 
The resulting structural robustness of the channels and the control system are shown in Table 3. Information associated with Table 3 is shown in Figs. 9-11.

In this particular case, $h_{2}(s)$ has the following form:

$h_{2}(s)=\frac{0.00916(s+0.025)(s+0.0604)(s-0.1815)}{(s+0.05849)(s+0.03408)(s-0.0381)\left(s^{2}+0.3256 s+0.03305\right)}$.

It must be stressed the fact that $h_{2}(s)$ should contain one RHPP, which is achieved due to the fact that $k_{21}(s) g_{12}(s)$ does not have any RHPP and its Nyquist plot encircles the point $(-1,0)$ once clockwise. The counterclockwise encirclement to the point $(1,0)$ of the Nyquist plot of $\gamma_{b}(s)$ is also preserved by $\gamma_{b}(s) h_{1}(s)$ and $\gamma_{\mathrm{b}}(s) h_{2}(s)$ as shown in Fig. 10(a).
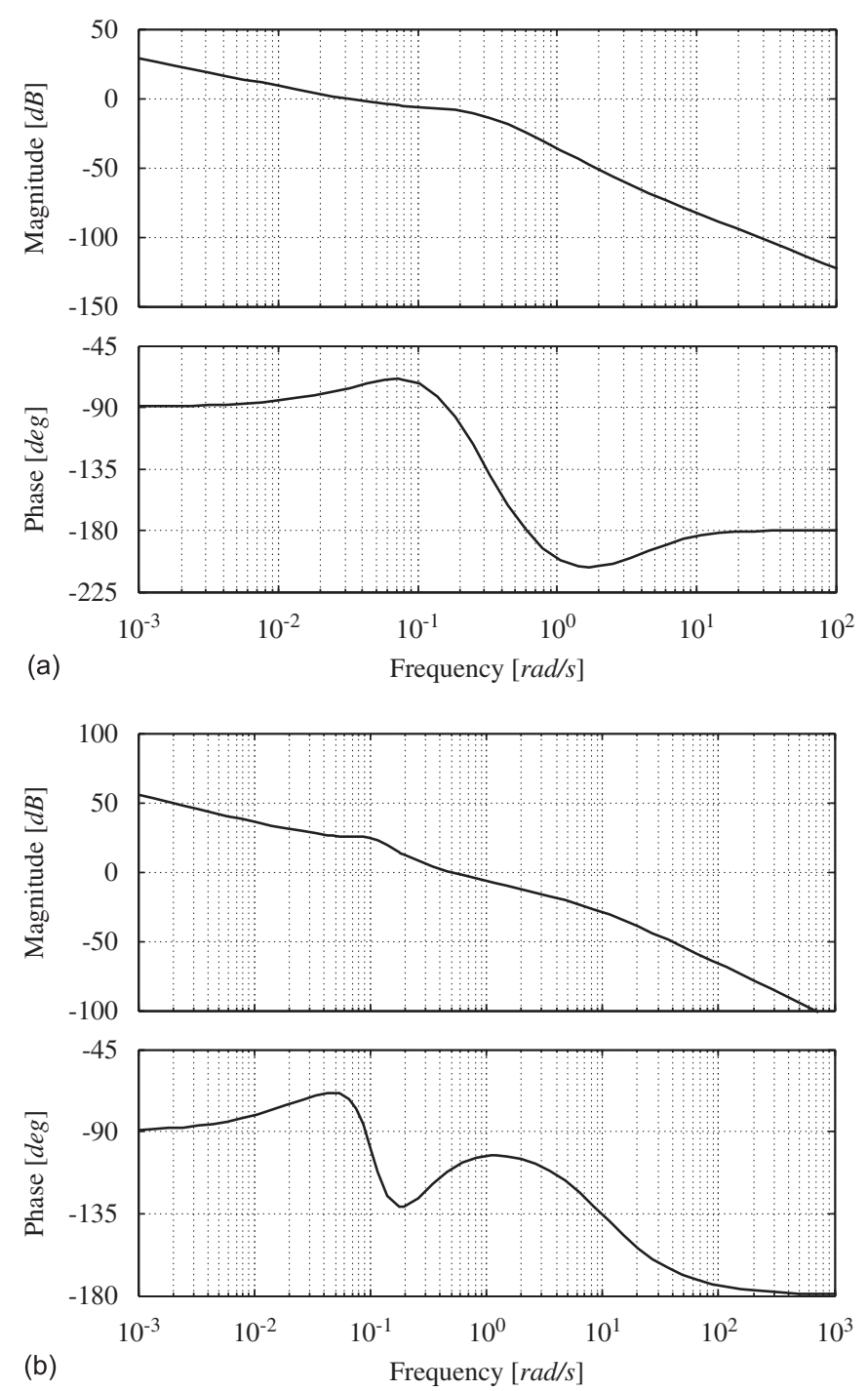

Fig. 8. (a)Bode diagram of $C_{1}(s)$ (depth) with $\gamma_{\mathrm{a}}(\mathrm{s})$, (b) Bode diagram of $C_{2}(s)$ (pitch) with $\gamma_{\mathrm{a}}(s)$.
In order to avoid sharp responses of the controller to step changes in depth, the reference is filtered according to: $z_{2}(s) / r_{2}(s)=0.0004 /\left(s^{2}+0.04 s+0.0004\right)$.

The time responses for both designs with $\gamma_{\mathrm{a}}(s)$ and $\gamma_{\mathrm{b}}(s)$ are compared in Fig. 12. The desired pitch angle is zero, whereas for the submarine depth, the step response is presented, which is representative for all the depth references. From the figure, it can be appreciated that the response obtained with $\gamma_{\mathrm{b}}(s)$ presents better performance than that obtained by means of $\gamma_{a}(s)$. The submarine depth converges to the desired reference with no overshooting. In addition, either the depth and the pitch angle reaches the desired behaviour in reasonable time.

The fact of obtaining a better submarine response by using $\gamma_{\mathrm{b}}(s)$ is a remarkable result, due to the fact that the input-output pairing associated with $\gamma_{\mathrm{b}}(s)$ is usually avoided in previous works.
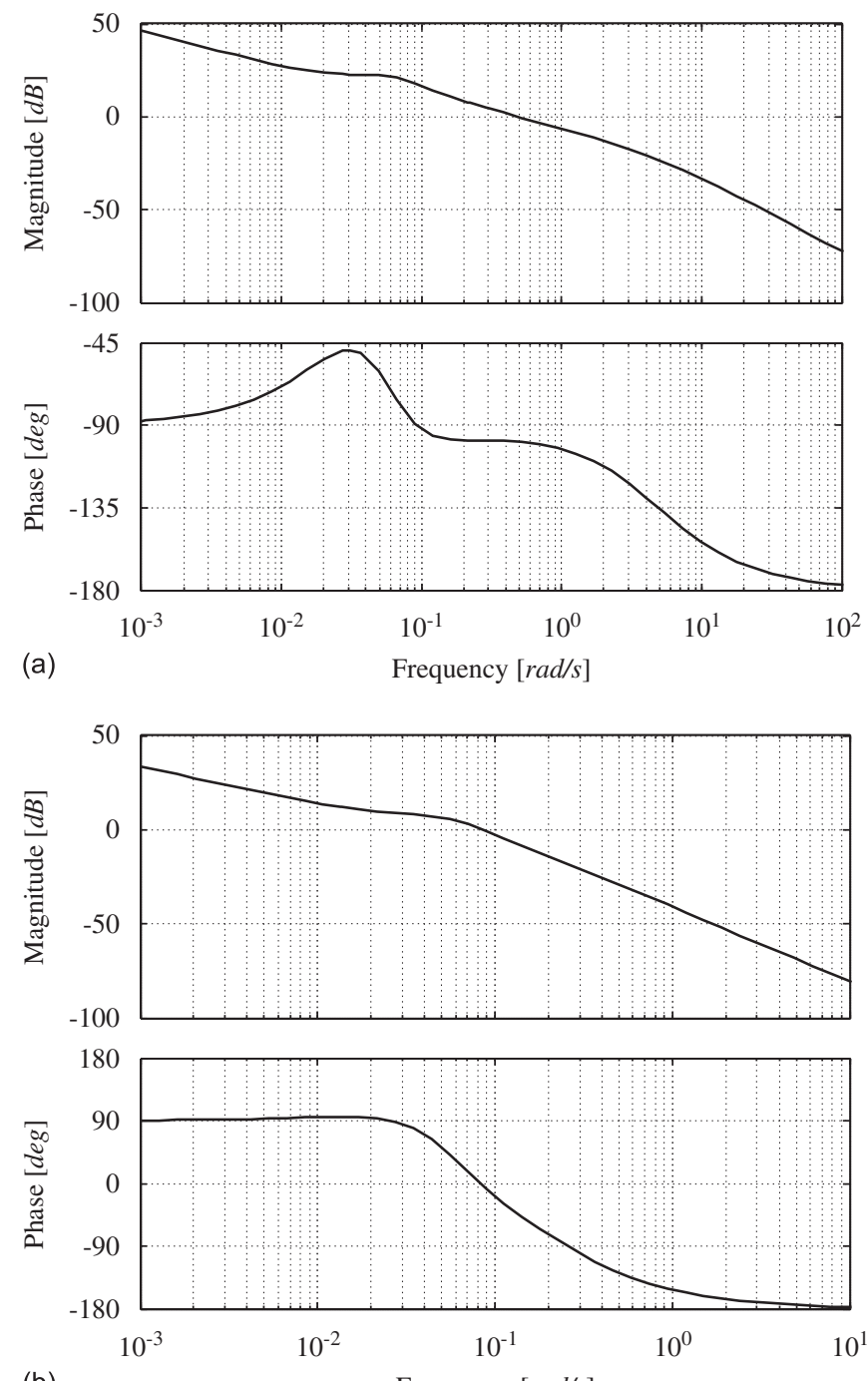

(b)

Frequency $[\mathrm{rad} / \mathrm{s}]$

Fig. 9. (a) Bode diagram of $k_{12}(s) g_{21}(s)$, (b) Bode diagram of $k_{21}(s) g_{12}(s)$.

Table 3

Structural robustness of the channels and control system using $\gamma_{\mathrm{b}}(s)$

\begin{tabular}{lccccc}
\hline Measure & $C_{1}(s)$ & $k_{11}(s) g_{11}(s)$ & $\gamma_{\mathrm{a}}(s) h_{2}(s)$ & $c_{2}(s)$ & $\gamma_{\mathrm{a}}(s) h_{1}(s)$ \\
\hline Bandwidth (rad/s) & 0.5 & 0.5 & - & 0.04 & 0.086 \\
Gain margin (dB) & 20 & $\infty$ & 5.15 & $\infty$ & $\infty$ \\
Phase margin (deg) & 82 & 100 & 26 & 77 & 150 \\
\hline
\end{tabular}



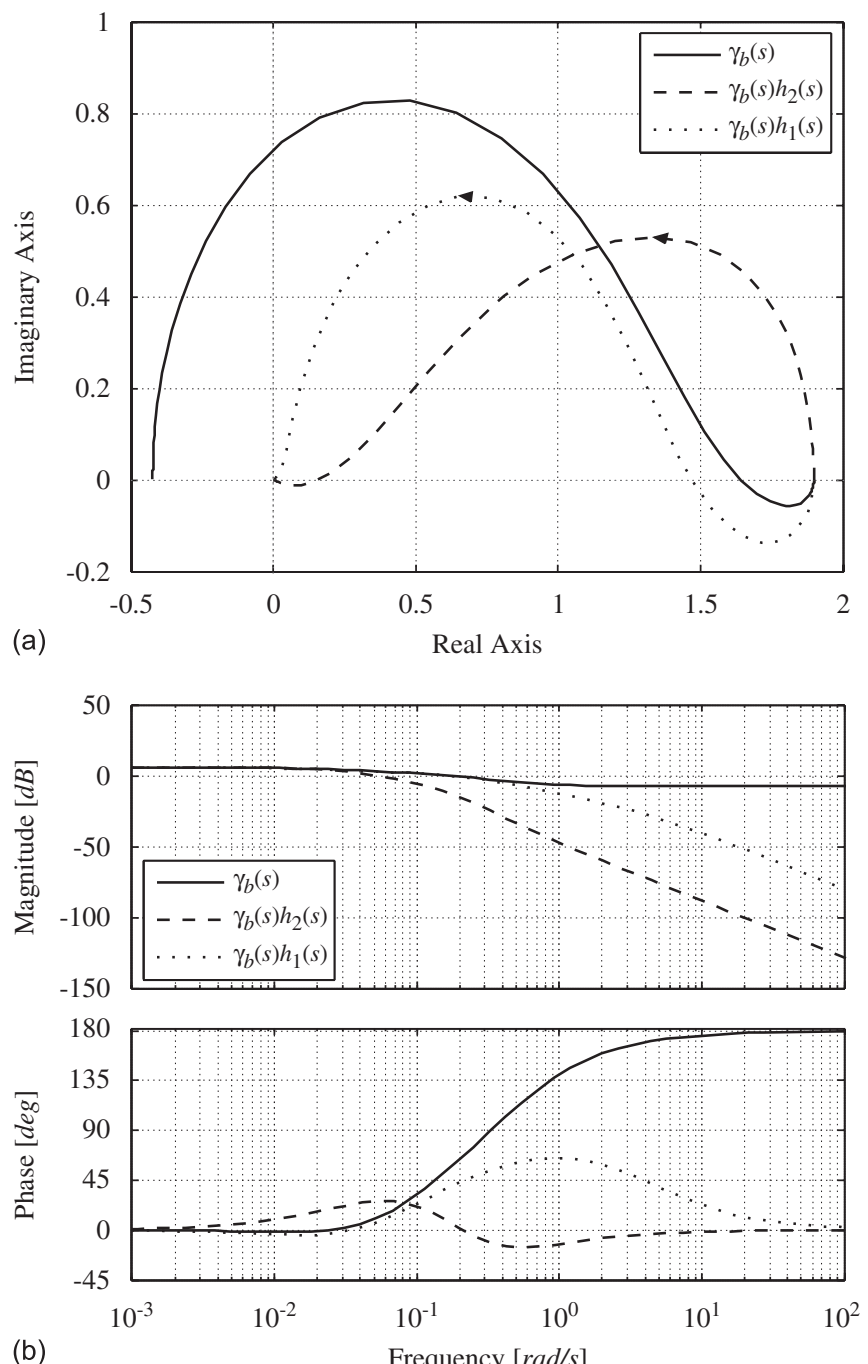

Fig. 10. (a) Nyquist diagrams of $\gamma_{\mathrm{b}}(s) h_{2}(s)$ and $\gamma_{\mathrm{b}}(s) h_{1}(s)$, (b) Bode diagrams of $\gamma_{\mathrm{b}}(s) h_{2}(s)$ and $\gamma_{\mathrm{b}}(s) h_{1}(s)$.

\subsection{ICAD design benefits}

One of the main aspects on the design of control design is the definition of customer specifications. Once the designer has a clear task, a framework for assessing the accomplishment of the goals is indeed needed. In that sense, ICAD provides a framework in which it is possible to analyse the system capabilities in terms of the control design. This is an aspect that allows to meet the goals avoiding over-design and not necessary complicated controllers. It should be remarked that under any design method it is possible to satisfy customer specifications. The performance of the controllers reported in Licega-Castro and van der Molen (1995a, b) is practically the same. Nevertheless, the difference of the complexity of the controllers is remarkable. This aspect is crucial for engineering applications. Since it is common to perform design adjustments in situ, the selection of weight functions and optimisation programmes is difficult to perform when complicated designs and analysis methods are used.

Remark 3. Phase and gain margins are indeed really good measurements of robustness. For instance, it is possible to find a system with good stability margins values and very bad nominal sensitivity function. This is pointed out in Goodwin et al. (2001). Nevertheless, the stability margins shown in Tables 2 and 3 need
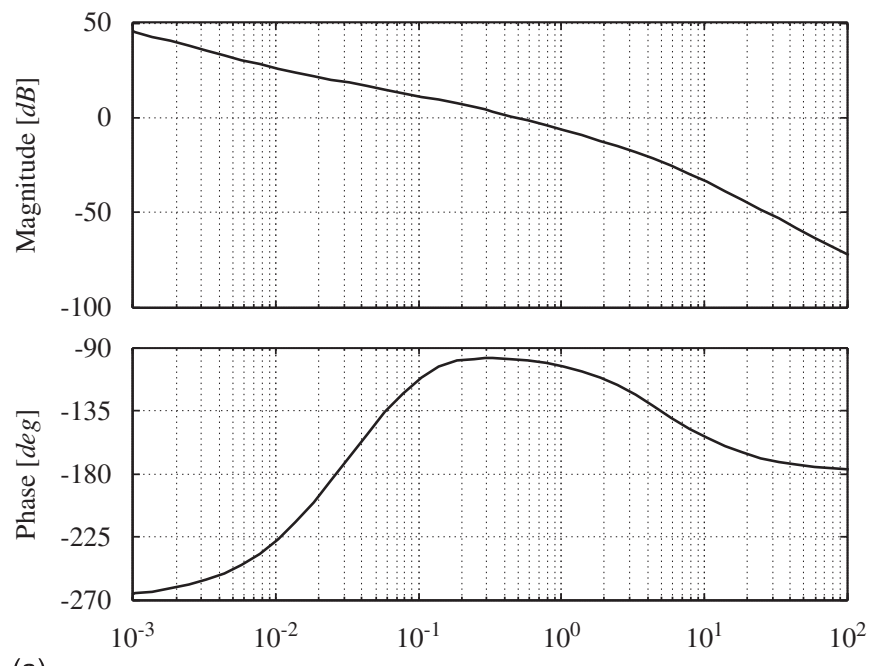

(a)
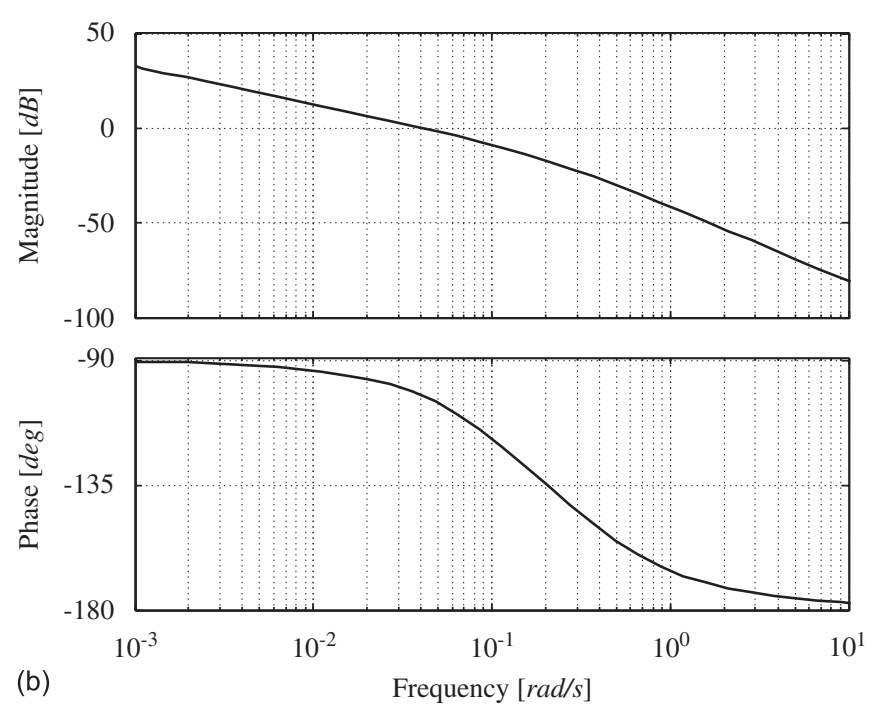

Fig. 11. (a) Bode diagram of $C_{1}(s)$ (pitch) with $\gamma_{\mathrm{b}}(s)$, (b) Bode diagram of $C_{2}(s)$ (depth) with $\gamma_{\mathrm{b}}(s)$.

to be associated with the corresponding Bode plots. That is, if the path during the roll-off of the Bode plots presents bumps or curly trajectories, the information of the tables is worthless. Consequently, the fact that the Nyquist plot does not pass near the critical point should be interpreted as acceptable roll-off behaviour, and achieving such characteristics is part of the design process. Therefore, the tables presented should be considered together with the corresponding Nyquist and Bode plots.

\section{Conclusion}

In this paper, the analysis and the design of multivariable depth-keeping controllers for a class of submarines have been presented. The analysis and design are set up in the framework of individual channel analysis and design. The main characteristics of the design procedure proposed here are:

- The application of Bode and Nyquist classical methods for a multivariable control system.

- The establishment of the conditions for evaluating the controller robustness using the reliable classical gain and phase margins concepts. 


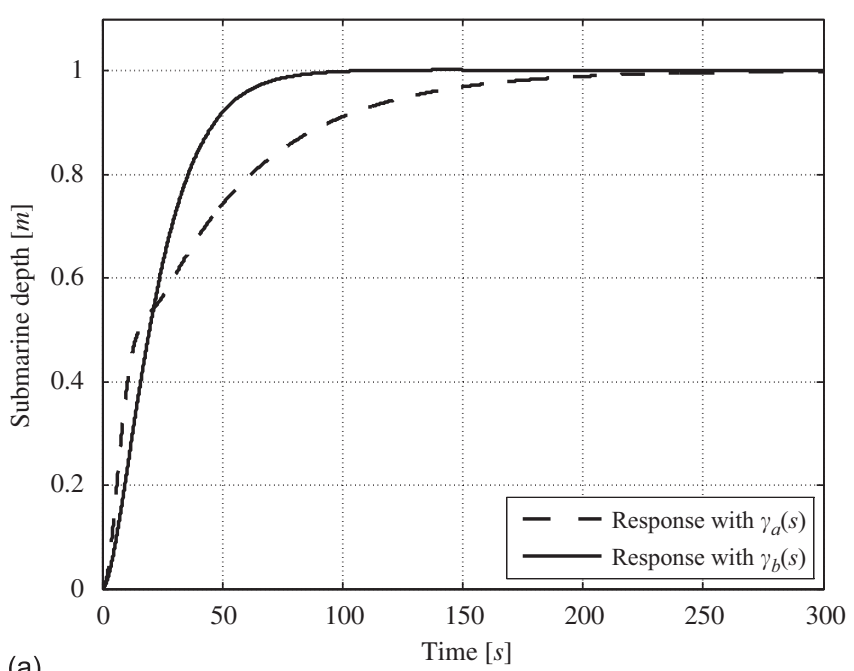

(a)

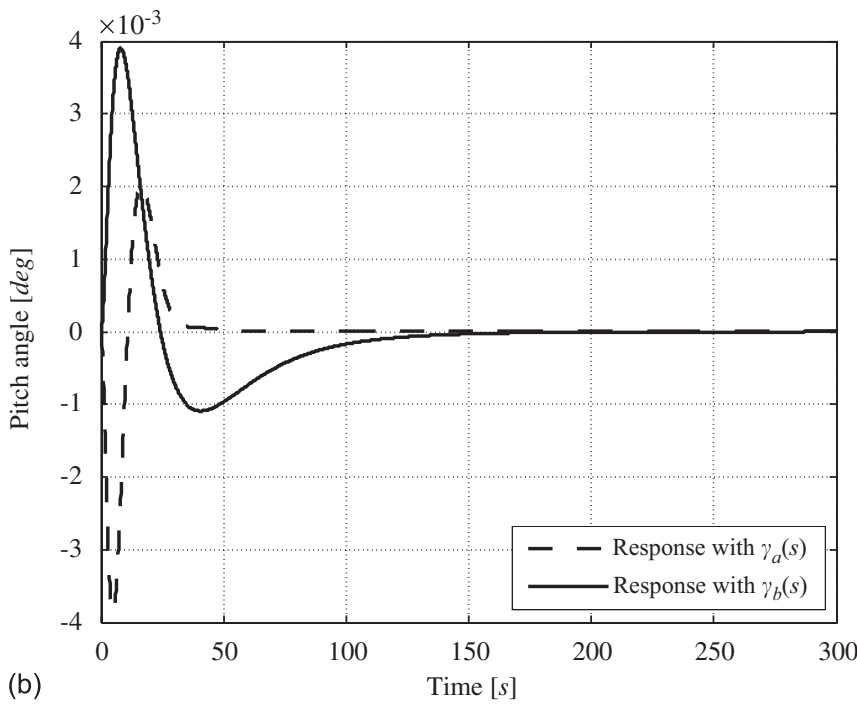

Fig. 12. (a) Step response for the controlled submarine depth with $\gamma_{b}(s)$ and $\gamma_{a}(s)$, (b) controlled pitch angle with $\gamma_{\mathrm{b}}(s)$ and $\gamma_{\mathrm{a}}(s)$.

- The design goals have been achieved by means of diagonal low-order controllers (there is no need for high-order nondiagonal controllers).

- A clear and transparent design procedure has been established, which together with the low order of the controllers, facilitates further tuning and implementation.

It is also shown that, by analysing the multivariable structure function, fixed minimum-phase stable controllers which stabilise the system exist for each set of input-output channel configuration. The key issue of this result is that the existence of diagonal stabilising controllers does not rely on the stabilisation of the diagonal elements.

\section{Acknowledgements}

This research was founded by the MOD under Grant no. ASE045 and SERC Grant no. GR/F/92435.

\section{Appendix}

Proof of Proposition 1. The stability of $y_{\mathrm{i}}(s)$ is determined by the poles of the transfer functions $R_{\mathrm{i}}(s), P_{\mathrm{i}}(s)$, and $Q_{\mathrm{i}}(s)$.
The sets $S_{\mathrm{R}}=$ \{poles of $\left.R_{\mathrm{i}}(s)\right\}$ and $S_{\mathrm{P}}=$ \{poles of $\left.P_{\mathrm{i}}(s)\right\}$ are both the same. That is, $S_{R}=S_{P}=$ zeros of $\left.1+C_{i}(s)\right\}$.

Moreover, the set of zeros of $P_{\mathrm{i}}(s)$, which are the poles of $C_{\mathrm{i}}(s)$, is defined by: $Z_{\mathrm{P}}=$ \{poles of $k_{\mathrm{ii}}(s), g_{\mathrm{ii}}(s), g_{\mathrm{ij}}(s), g_{\mathrm{ji}}(s), k_{\mathrm{jj}}(s)$, and $h_{\mathrm{j}}(s)$ \}. On the other hand, the set of poles of $Q_{i}(s)$ is $S_{Q}=$ \{poles of $g_{\mathrm{ij}}(s), k_{\mathrm{jj}}(s)$, and $\left.h_{\mathrm{j}}(s)\right\}$. Therefore, $S_{\mathrm{Q}} \subset Z_{\mathrm{P}}$. Thus, the poles of $Q_{\mathrm{i}}(s)$ cancel with the zeros of $P_{\mathrm{i}}(s)$. That is, the set of poles of (10) is the same as $S_{\mathrm{R}}=S_{\mathrm{P}}=$ zzeros of $\left.1+C_{\mathrm{i}}(s)\right\}$. Therefore, if $k_{\mathrm{ii}}(s)$ stabilises the closed-loop transfer function $R_{\mathrm{i}}(s)$ then it also stabilises (10).

\section{References}

Akbar, M.A., Leithead, W.E., O’Reilly, J.O., Robertson, S.S., 1994. Design of robust controllers for a 3-input 3-output supersonic aircraft powerplant using ICD. In: Proceedings of the 3rd IEEE Conference on Control Applications. Glasgow, UK, pp. 95-99.

Arentzen, E.S., Mandel, P., 1960. Naval architectural aspects of submarine design. The Society of Naval Architects and Marine Engineers Transactions 68.

Booth, T. 1983. Optimal depth control of an underwater vehicle under a seaway. Proceedings of the Royal Institution of Naval Arquitects. International Symposium on Naval Submarines. London, pp. 17-19

Bovis, A.G., 1988. Optimal control, safety and silence. Trends in design of manoeuvring systems for French submarines. Proceedings of Warship 88 International Symposium on Conventional Naval Submarines. London, UK.

Braugnier, W., 1966. Automatic depth control of submarine split plane mode. Naval Ship Systems Command Technical News 15, part 7, July.

Burges, R.F., 1975. Ships Beneath the Sea: A History of Submarines and Submersibles. McGraw-Hill, New York.

Daniel, C.J., 1981. Submersible Vehicle Control. M. Phil. Thesis, University of Cambridge, UK.

Daniel, C.J., Richards. R.J., 1982. A multivariable controller for depth control of a submersible vehicle. Proceedings of the Institute of Measurement and Control Conference: Applications of Multivariable System Theory, October 1982.

Daniel, C.J., Richards. R.J., 1983. Control of Underwater Vehicles. Department of Engineering, University of Cambridge, UK, Report no. 2020/0156, August.

Dudgeon, G.J.W., Gribble, J.J., 1998. Helicopter translational rate command using individual channel analysis and design. Control Engineering Practice 6 (1), 15-23.

Dudgeon, G.J.M., Leithead, W.E., O'Reilly, J., McDonald, J.R., 2000. Prospects for the decentralised control of small-scale power networks with embedded generation. Proceedings of the Power Engineering Society Winter Meeting, 1399-1404.

Edwards, F.V., Dudgeon, G.J.W., McDonald, J.R., Leithead, W.E., 2000. Dynamics of distribution networks with distributed generation. In: Proceedings of the Power Engineering Society Summer Meeting, pp. 1032-1037.

Fadlalmula, Z., Robertson, S.S., O'Reilly, J., Leithead, W.E., 1998. Individual channel analysis of the turbogenerator with a power system stabilizer. International Journal of Control 69 (2), 175-202.

Freudenberg, J.S., Looze, D., 1988. Right half plane poles and zeros and design tradeoffs in feedback systems. IEEE Transactions in Automatic Control 30, 555-565.

Goodwin, G.C., Graebe, S.F., Salado, M.E., 2001. Control System Design. PrenticeHall, USA.

Gueler, G.F., 1989. Modelling, design, and analysis of an autopilot for submarine vehicles. International Shipbuilding Progress 36, 51-85.

Keel, L.H., Bhattacharyya, S.P., 1997. Robust, fragile, or optimal? IEEE Transactions on Automatic Control 42 (8), 1098-1106.

Leithead, W.E., O'Reilly, J., 1991a. Performance issues in the individual channel design of 2-input 2-output systems. Part 1: Structural issues. International Journal of Control 54, 47-82.

Leithead, W.E., O'Reilly, J., 1991b. Uncertain SISO systems with fixed stable minimum-phase controllers: relationship of closed-loop systems to plane RHP poles and zeros. International Journal of Control 53, 771-798.

Leithead, W.E., O'Reilly, J., 1992a. Performance issues in the individual channel design of 2-input 2-output systems. Part 2: robustness issues. International Journal of Control 55, 3-47.

Leithead, W.E., O'Reilly, J., 1992b. m-Input m-Output feedback control by individual channel design. Part 1. Structural Issues. International Journal of Control 56 (6), 1347-1397.

Leithead, W.E., O'Reilly, J., 1994. Investigation of the ICD structure of systems defined by state space models. International Journal of Control 60 (1), 71-89.

Liceaga-Castro, J.U., 1994. Helicopter Flight Control by Individual Channel Design. Ph.D. Dissertation. University of Glasgow, UK.

Liceaga-Castro, E., Liceaga-Castro, J., 1998. Submarine depth control by individual channel design. In: Proceedings of the 37th IEEE Conference on Decision and Control, Tampa, Florida, USA, pp. 3183-3188.

Liceaga-Castro, E., van der Molen, G., 1995a. A submarine depth control system design. International Journal of Control 61 (2), 279-308.

Liceaga-Castro, E., van der Molen, G., 1995b. Submarine $H^{\infty}$ depth control under wave disturbances. IEEE Transactions on Control Systems Technology 3 (3), 338-346. 
Lively, K.A., 1983. Multivariable Control System Design for a Submarine. M.Sc. Thesis, Massachusetts Institute of Technology, USA, May.

Marshfield, W.B., 1991. Submarine periscope depth-keeping using an $H^{\infty}$ controlle together with sea noise reduction notch filters. Proceedings of the Institute of Measurement and Control Symposium: Robust Control System Design Using $H^{\infty}$ and Related Methods Meeting, Cambridge, UK, pp. 3183-3188.

Marshfield, W.B., 1992. Submarine data for the use in autopilot research. Defense Research Agency, Haslar, Gosport, Hampshire, U.K. Private communication.

Marshfield, W.B., Hirom, C., Meek, S.F., 1992. Submarine SEA, to calculate the forces and moments on a submerged submarine due to waves. Defense Research Agency, Haslar, Gosport, Hampshire, U.K. Private communication.

Nesline, F.W., Zarchan, P., 1982. Why modern controllers can go unstable in practice. In: Proceedings of the AIAA Guidance and Control Conference. San Diego, California, USA

Nonweiler, T.R.F., 1961. The stability and control of deeply submerged submarines. Transactions RINA.

O'Reilly, J., Leithead, 1991. Multivariable control by individual channel control International Journal of Control 54, 1-46.

Presentation to RDM by the Submarine Control Group of Ferranti Naval Systems, 1993. Ferranti International, Ref. 15106-60227-45, North Crawley Road, New Port Pagnell, Bucks MK16 9HT, UK, March.

Richards, R.J., Stoten, D.P., 1981. Depth control of a submersible vehicle. International Shipbuilding Progress 28, 30-39.

Spencer, J.B., 1982. Stability and control of submarines. Parts I-IV. Reprint of the Royal Naval Scientific Science 23, 187-205, 265-281, 327-345.
Ugalde-Loo, C.E., Liceaga-Castro, E., Liceaga-Castro, J., 2005. $2 \times 2$ Individual channe design Matlab toolbox. In: Proceedings of the Joint 44th IEEE Conference on Decision and Control and European Control Conference, Sevilla, Spain.

Ugalde-Loo, C.E. Vanfretti, L, Liceaga-Castro, E. Acha, E, 2006. Synchronous generators control: From the traditional perspective to the ICAD framework. Proceedings of the International Conference Control (UK-ACC), Glasgow, Scotland, UK

Ugalde-Loo, C., Acha, E., Liceaga-Castro, E., Liceaga-Castro, J., 2008. Fundamental analysis of the static VAR compensator performance using individual channel analysis and design. International Journal of Emerging Electric Power Systems $9(2), 1-35$.

Williams, S.J., Marshfield, W.D., 1990. $H^{\infty}$ multivariable design of a submarine depth control system. Proceedings of the Symposium of the Institute of Measurement and Control: Application of Multivariable System Techniques, Bradford, UK, pp. 194-205.

Williams, S.J., Marshfield, W.D., 1991a. Submarine periscope depth-keeping using an $H^{\infty}$ controller together with sea reduction notch filters. Transactions of the Institute of Measurement and Control 13 (5), 233-240.

Williams, S.J., Marshfield, W.D., 1991b. A full envelope submarine depth control system incorporating switched $H^{\infty}$ controllers. Proceedings of the American Control Conference, Boston, USA.

Yanushevsky, R., 2008. Modern Missile Guidance. CRC Press, Taylor and Francis, Boca Raton, London, New York.

Zhao, G., Yan, Y., 1989. Multivariable control for submarine manoeuvring in vertical plane. Shipbuilding of China Transactions, Part 107, October. 